www.jmscr.igmpublication.org

Impact Factor 5.84

Index Copernicus Value: 83.27

ISSN (e)-2347-176x ISSN (p) 2455-0450

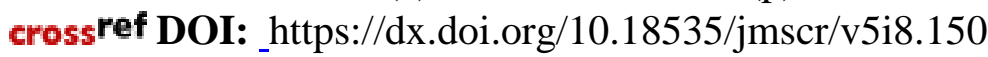

Journal Of Medical Science And Clinical Research

\title{
Surgical Management of Neglected Tendo Achilles Tendon Rupture with Gastrosoleus turn down Flap
}

Authors

\section{Dr Konchada Srikant ${ }^{1}$, Dr Basanta Kumar Behera ${ }^{2}$, Dr Sandeep Pradhan ${ }^{3}$}

${ }^{1,3}$ Senior Resident, Dept of Orthopaedics, Kalinga Institute of Medical Sciences, Bhubaneswar KIIT University

${ }^{2}$ Professor, Dept of Orthopaedics, Kalinga Institute of Medical Sciences, Bhubaneswar, KIIT University Corresponding Author

Dr Basanta Kumar Behera

Professor, Dept of Orthopaedics, Kalinga Institute of Medical Sciences, Bhubaneswar, KIIT University Phone: 9437248843, Email: basantaorth@gmail.com

\begin{abstract}
Introduction: Tendo Achilles rupture is one of the most common ruptured tendons. Late presentations are not uncommon due to negligence or misdiagnosis and can affect daily living activities. Management of such neglected ruptures are difficult with multiple treatment options depending on rupture gap and tissue status. We present the results of managing such cases with technique of reconstruction with gastrosoleus turn down flap.
\end{abstract}

Patients and Methods: 18 patients of neglected tendo achilles rupture were operated between 2010 to 2015 and considered for the study after meeting inclusion criteria. We reconstructed with harvesting of gastrosolues turn down flap with variable gaps. Post operatively immobilised in below knee cast, followed by ankle strengthening exercises. AOFAS score and modified Rupp scores were used to evaluate the results

Results: At final follow-up, all the patients could return to their daily activities. The AOFAS scores increased from an average of 65.6 preoperatively to 95.2 postoperatively. Modified Rupp score was excellent in 9 patients. One case had superficial skin necrosis which healed with secondary suturing. None of the case had re rupture with a mean follow up of 46.9 months.

Conclusion: Achilles tendon is one of the most common ruptured tendons and can be debilitating if left untreated. Management of neglected ruptures is difficult with multiple treatment options depending on the rupture gap and state of the remaining tissue. Reconstructing with turning down the harvested gastrosoleus flap can bridge the ruptured gap of varying size, restore length, sparing the foot \& ankle muscles with reasonable good outcome

Key Words: Tendo Achilles, Neglected, Rupture, Gastrosoleus, Turn Down Flap.

\section{Introduction}

Tendo Achilles rupture is one of the most common tendon rupture of lower $\operatorname{limb}^{1}$ and has many treatment options. ${ }^{2}$ Treatment was initially conservative but has been surgical since past two decades for early rehabilitation and increased patient demand. ${ }^{3,4}$

Neglected tendo achilles ruptures are not uncommon in orthopaedic practice. ${ }^{5}$ Initial symptoms often diminish after acute rupture. Lack 
of pain and sometime with no obvious loss of plantarflexion due to partial rupture/recruitment of other plantar flexors can lead to misdiagnosis and neglected with delayed treatment.

Neglected ruptures can heal without any surgery with abundant scar bridging the ruptured gap which can lead to reduced plantar flexion power. ${ }^{8}$ Large defect, bridging scar, surrounding fibrous tissue, contracted and wasted triceps surae complex all make management of neglected ruptures difficult. ${ }^{9}$ Different surgical reconstructtion methods have been used depending on the gap and state of the remaining tendon which are always difficult surgically with long recovery time than repairing an acute rupture posing challenge for both for the surgeon and the patient. ${ }^{10}$

We routinely treat the neglected tendo achilles ruptures with gap with the technique of reconstruction with gastrosoleus turn down flap and the purpose of this study was to report results and complications of our case series with this technique.

\section{Patients and Methods}

Between February 2010 to May 2015, 20 patients with neglected tendo achilles rupture were treated with reconstruction with turn down gastrosoleus flap technique. Followed up for at least 12 months, two patients lost in follow up, so 18 patients were considered for study analysis and results.

Inclusion criteria were skeletally mature, neglected rupture $>6$ weeks, unilateral, rupture at watershed zone (zone of avascularity) and previously not treated. Exclusion criteria were skeletally immature, acute ruptures, bilateral, avulsion type and re-ruptures.

The study group comprised of 15 male and 3 female patients in the age range from 21 to 63 years. Diagnosis was made on clinical examination findings like presence of palpable gap, decreased plantar flexion power and a positive calf squeeze test. Plain radiograph in antero posterior and lateral were taken to rule out any avulsion fractures.

\section{Operative technique}

All patients were operated under spinal anesthesia with tourniquet on. Patients were positioned in prone position. Medial incision parallel over medial border of lower stump preferred over midline incision over tendon to overcome wound healing problems if any directly over tendon. The incision gradually centered and extended upto the musculo tendinous junction of triceps surae in curvilinear fashion. The sural nerve was safely included in lateral flap. Skin flap was handled with care. Peritenon was incised in midline. Ruptured site was identified which was frequently bridged with scar tissue. Carefully scar tissue excised and tendon ends freshened. Gap was measured keeping ankle in 30 degree plantar flexed, and also the distance of rupture site from its insertion into calcaneum.

A central turn down flap of width $1.5 \mathrm{~cm}$ is harvested from the musculotendinous junction which is based distally upto $2 \mathrm{~cm}$ from the proximal end of the rupture. Excess tissue is trimmed from the harvested flap. A slit is made in the distal stump of tendo Achilles through which the harvested flap is turned down and is inserted and taken out other side in pulvertaft technique. Similarly a slit is made in proximal stump and this flap is inserted in slit and taken out to other site. Slit and passage of harvested flap is done multiple times on either side of stump till end of the flap is reached and at each pulvertaft junction sutured knot is placed with ethibond no 2 suture (figues 14). These multiple loops will bridge the gap trying not to overcome gap with ankle in full plantar flexion making rehabilitation later difficult so ankle kept in neutral or slightly plantar flexed. Distal most part of harvested flap is made thinned out and spread in fanned out manner spreading the bridging site and slit junctions and sutures with vicryl no. 2-0.

Wound was closed in layers with careful handling of flap specially the distal part keeping a closed suction drain in situ. Tourniquet was deflated. Post closure an anterior above knee slab was 
applied with ankle in neutral and knee in 30 degree flexed position.

\section{Post operative care}

The anterior slab applied helped us for easy dressing of the wound. Sutures were removed at 14 post operative day. Patient was discharged with a below knee plaster cast in ankle neutral and advised non weight bearing for 3 weeks. Patients were called for follow up after 3 weeks discharge. Plasters were removed, wound inspection done and below knee synthetic cast was applied for weight bearing for next 3 weeks.

Post cast removal patients were encouraged to do isokinetic strengthening, isometric and proprioceptive exercises under the guidance of a physiotherapist.

\section{Evaluation}

All the studied patients were called for follow up looking for the integrity of repair and functional status post repair. At each follow up ankle range of movement, calf thickness compared to opposite limb, and neurological status of foot and ankle noted. At the last follow up we assessed factors specific to the repair status Achilles tendon rupture like ability of patient standing on tiptoe, ability to perform repeated toe raises and single limb hopping. Patient evaluation was performed with the pre- and postoperative American Orthopaedic Foot and Ankle Society (AOFAS) ankle-hindfoot scores $^{11}$ and for subjective satisfaction we used the kerkhoff's modified Rupp score $^{12}$ (table 1)to evaluate the at the most recent follow-up. Results of this scoring were rated as excellent (>30 points), good (15-30points), fair (5-15points), and poor ( $<5$ points). Possible complications like re rupture, wound dehiscence were also looked for and noted. The collected data were analysed for statistical evaluation using SPSS 20.0 version Software.

\section{Results}

18 patients were considered for the study out of 20 cases operated as 2 lost in follow up. 15 were male and 3 female. The mean follow up time was 46.9 months (range 15-84 months). Mean time to surgery was 5.16 months (range 1.5-12) and with average rupture gap of $5.33 \mathrm{~cm}$ (range $3-8 \mathrm{~cm}$ ) (table 2). On comparing ankle range of movement with the uninjured side, the mean plantar flexion on injured side was 131 degree(115-140) compared to 134 degree (120-150) on uninjured side similarly mean dorsi flexion on injured was 13 degree(5-20) and 15(10-20) on uninjured side. The mean calf diameter was $36.8 \mathrm{~cm}(30-44)$ on injured side and $39.1 \mathrm{~cm}(32-48)$ on uninjured site (table 3).

At final follow-up, all the patients could return to their daily activities and could perform single leg hopping for 30seconds, repeated heel raises, and heel standing which no patients were able to do so before surgical reconstruction. Post operative ankle range of movement too regained equal to opposite normal side except in two patients where dorsi flexion short by 10 degree persisted compared to opposite site.

The mean AOFAS ankle-hindfoot scores improved from 65.6 (range, 44-88) preoperatively to 95.2 (range, 79-100) at last follow up and found to be statistically significant $(\mathrm{p}<0.001)($ table 4,5$)$. The statistical significance in difference between preoperative and postoperative AOFAS Scores were done using Wilcoxon Signed Ranks Test, where $\mathrm{p}<0.005$ was considered significant. Modified Rupp's score was excellent in 9, good in 6 , and fair in 3, that means $83.3 \%$ patient's result considered good or excellent (table 6).

All patients returned to their daily activities and none had to change their job or activity modification. One patient developed superficial skin necrosis while healing of the surgical wound which was repaired uneventfully with secondary closure. None of the cases had re rupture of the reconstructed tendon. Two patients had hypertrophic operative scars leading to uncomfortable shoe wearing. None were disappointed or dissatisfied with their surgical reconstruction. 
Table 1: modified Rupp score for subjective evaluation

Subjective satisfaction

Excellent

Good

Satisfactory

Poor

Do you experience pain on bearing weight?

None

With extended weight bearing

With slight weight bearing

Continuous pain

Do you experience pain independent of bearing weight?

None

Pain associated with changes in weather

Pain sometimes associated with rest

Continuous pain

Has your ankle function decreased since the operation?

No

Reduction of muscle strength

Tendency to swelling

Tendency to cramp

Do you fear re rupture?

Yes

No

Do you have limitations in your work?

Does not apply

None

Minor

Major

Changed profession due to Achilles tendon problem

Do you have limitations in sporting activities?

Does not apply

None

Minor

Major

Stopped with the activity due to Achilles tendon problem -5

Total: >30 Excellent

15-30 Good

5-15 Fair

$<5$ Poor

Table 2 : patient details

\begin{tabular}{|l|c|c|c|c|c|}
\hline No. & Age & Sex & $\begin{array}{c}\text { Duration } \\
\text { months }\end{array}$ & $\begin{array}{c}\text { Defect in } \\
\text { cm }\end{array}$ & $\begin{array}{c}\text { Follow up } \\
\text { in months }\end{array}$ \\
\hline 1 & 57 & M & 5 & 6 & 84 \\
\hline 2 & 43 & M & 12 & 8 & 82 \\
\hline 3 & 40 & M & 3 & 5 & 74 \\
\hline 4 & 58 & F & 6 & 5 & 71 \\
\hline 5 & 21 & M & 1.5 & 4 & 67 \\
\hline 6 & 30 & M & 2 & 3 & 65 \\
\hline 7 & 63 & M & 5 & 5 & 60 \\
\hline 8 & 44 & M & 11 & 7 & 53 \\
\hline 9 & 50 & M & 7 & 5 & 51 \\
\hline 10 & 28 & M & 2 & 4 & 47 \\
\hline 11 & 55 & M & 1.5 & 5 & 36 \\
\hline 12 & 43 & M & 3 & 6 & 31 \\
\hline 13 & 40 & M & 2 & 5 & 26 \\
\hline 14 & 56 & M & 7 & 5 & 24 \\
\hline 15 & 44 & F & 5 & 5 & 23 \\
\hline 16 & 60 & M & 6 & 8 & 19 \\
\hline 17 & 52 & F & 10 & 5 & 16 \\
\hline 18 & 25 & M & 4 & 5 & 15 \\
\hline
\end{tabular}

Table 3 : measurement of calf diameter and range of movement in normal and injured side

\begin{tabular}{|l|c|c|c|}
\hline & $\begin{array}{c}\text { Calf } \\
\text { diameter(cm) }\end{array}$ & $\begin{array}{c}\text { Plantar } \\
\text { flexion(deg) }\end{array}$ & $\begin{array}{c}\text { Dorsi } \\
\text { flexion(deg) }\end{array}$ \\
\hline Normal side & $39.1(32-48)$ & $134(120-150)$ & $15(10-20)$ \\
\hline injured side & $36.8(30-44)$ & $131(115-140)$ & $13(5-20)$ \\
\hline
\end{tabular}

Table 4: post operative results

\begin{tabular}{|l|c|c|c|}
\hline No. & $\begin{array}{c}\text { Pre op AOFAS } \\
\text { score }\end{array}$ & $\begin{array}{c}\text { Post op } \\
\text { AOFAS score }\end{array}$ & $\begin{array}{c}\text { Modified Rupp } \\
\text { score }\end{array}$ \\
\hline 1 & 63 & 100 & 30 \\
\hline 2 & 71 & 100 & 32 \\
\hline 3 & 82 & 97 & 25 \\
\hline 4 & 44 & 79 & 14 \\
\hline 5 & 57 & 87 & 14 \\
\hline 6 & 63 & 100 & 32 \\
\hline 7 & 63 & 90 & 29 \\
\hline 8 & 58 & 88 & 20 \\
\hline 9 & 51 & 94 & 31 \\
\hline 10 & 50 & 97 & 31 \\
\hline 11 & 66 & 88 & 13 \\
\hline 12 & 88 & 100 & 32 \\
\hline 13 & 74 & 100 & 31 \\
\hline 14 & 66 & 100 & 31 \\
\hline 15 & 68 & 96 & 28 \\
\hline 16 & 73 & 98 & 25 \\
\hline 17 & 68 & 100 & 33 \\
\hline 18 & 76 & 100 & 32 \\
\hline Mean & 65.6 & 95.2 & 26.8 \\
\hline & & & \\
\hline
\end{tabular}

Table 5: statistical analysis of pre and post operative AOFAS Score

\begin{tabular}{|c|c|c|}
\hline & $\begin{array}{c}\text { Pre-op } \\
(\mathrm{n}=18)\end{array}$ & $\begin{array}{c}\text { Post-op } \\
(\mathrm{n}=18)\end{array}$ \\
\hline AOFAS score & $65.6 \pm 11.1(\mathrm{sd})$ & $95.2 \pm 6.2(\mathrm{sd})$ \\
\hline $\mathrm{p}<0.001$ (Highly significant) \\
\hline
\end{tabular}

Table 6: post operative modified Rupp score

\begin{tabular}{|l|c|c|}
\hline Modified RUPP score & No. of patients & \% of patients \\
\hline Excellent $(>30)$ & 9 & 50 \\
\hline Good $(15-30)$ & 6 & 33.3 \\
\hline Fair(5-15) & 3 & 16.7 \\
\hline Poor $(<5)$ & 0 & 0 \\
\hline
\end{tabular}

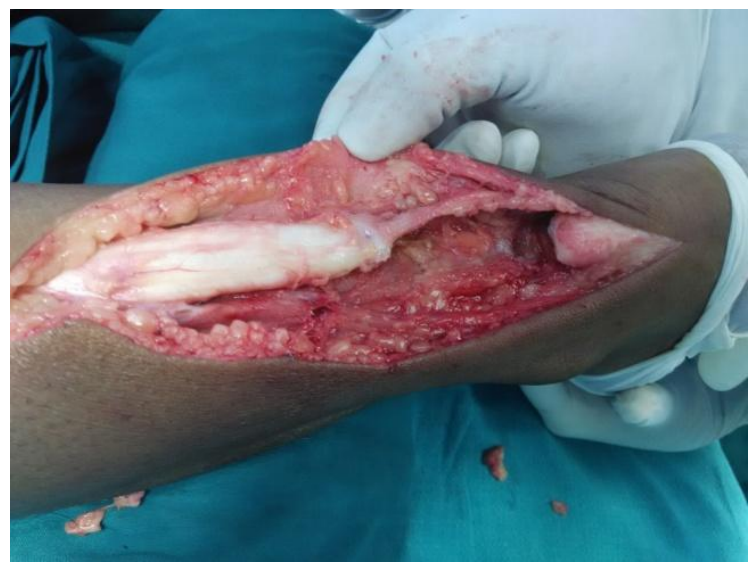

Figure 1: intraoperative finding of gap of $8 \mathrm{~cm}$ after excising scar tissue 


\section{JMSCR Vol||05||Issue||08||Page 26887-26893||August}

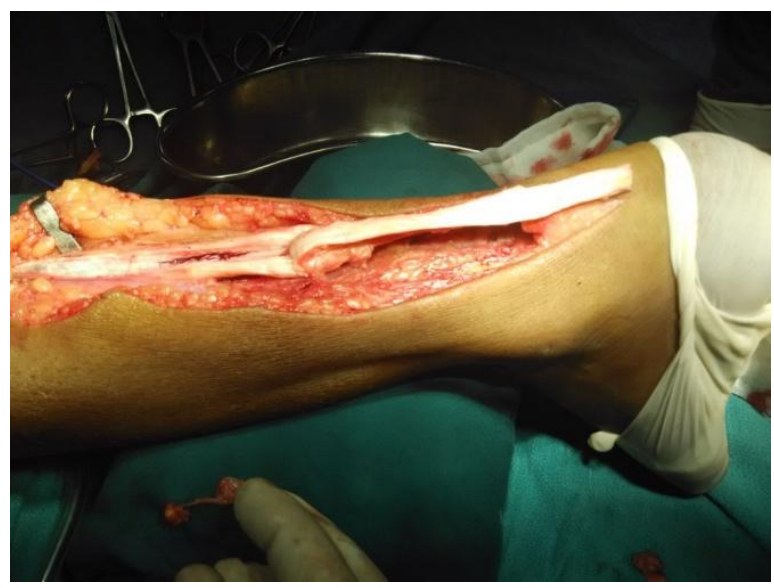

Figure 2: gastrosoleus flap harvested and turned down

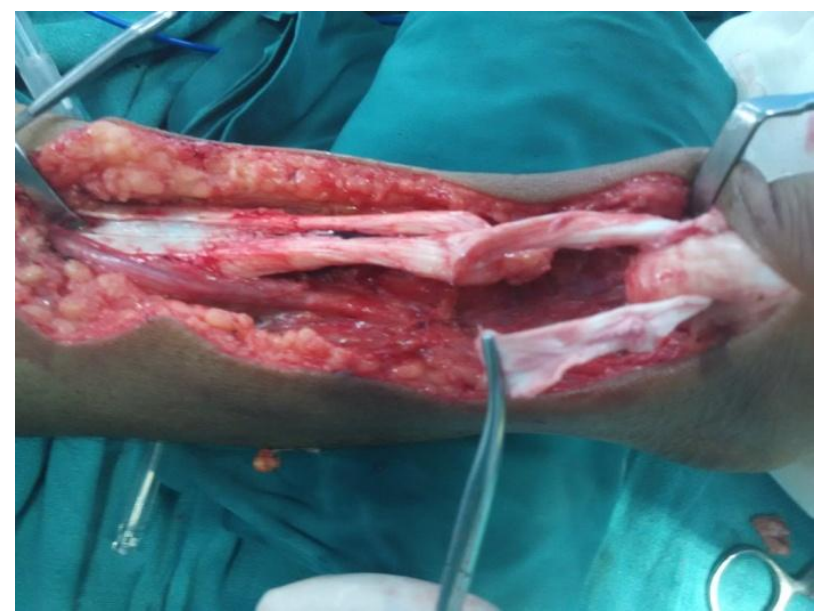

Figure 3: harvested flap passed through slit made in distal stump

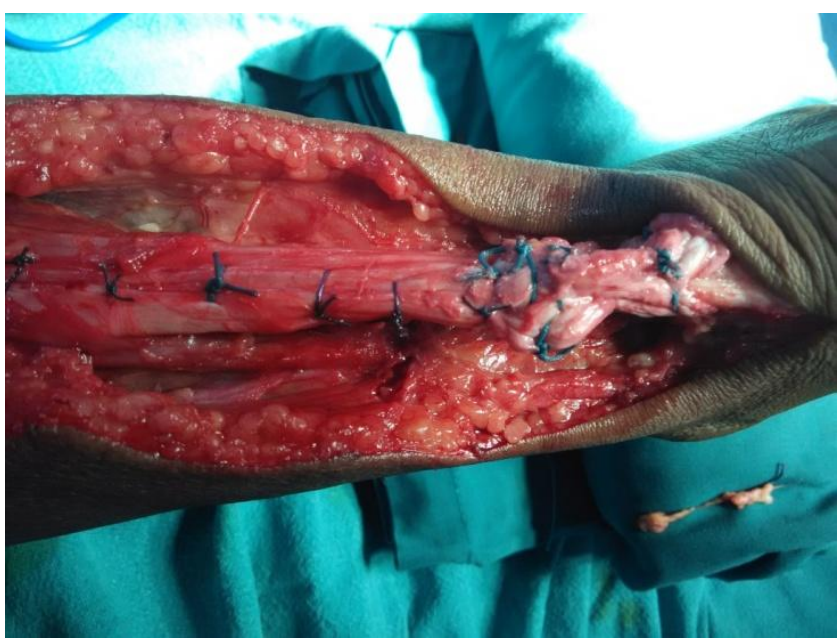

Figure 4: after bridging the gap
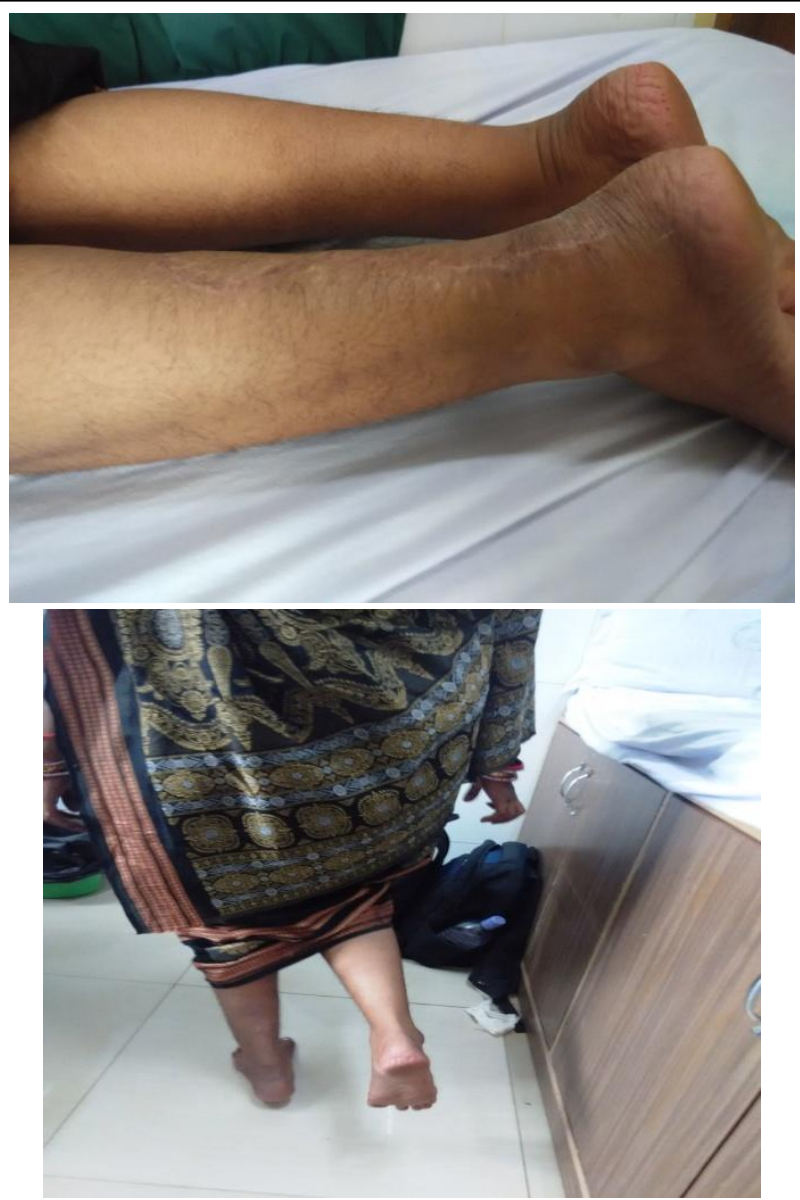

Figure 5, 6: clinical photograph of functional outcome at follow up

\section{Discussion}

Achilles tendon is one of the most common ruptured tendons and can be debilitating especially in high demand individuals. Apart from sports injury, age related risk factors do play an important role in rupture which is evident from theory of chronic degenerative changes based on histopathological examination of the tissue obtained from rupture site during surgery. ${ }^{13}$

Patients in our study had neglected rupture due to either not properly diagnosed with acute tendo Achilles rupture or due to diminishing symptoms after the acute episode and chronic rupture due to degenerative changes. Many methods have been described in literature for the reconstruction of neglected ruptures depending on the rupture gap between the ends. ${ }^{14,15}$ For the reconstruction basic requirement is to bridge the defect by tissue which can appose and unite the ends achieving continuity, strength to allow full range of movement with early rehabilitation. ${ }^{9}$ Simple end 
to end suture is difficult in gap situation especially when its significantly neglected and even if its possible rehabilitation is very much delayed leading to poor outcome. The most popular options for the management of neglected tendo Achilles ruptures with gap are V-Y repair ${ }^{16}$, Lindholm technique $^{17}$, and Bosworth technique ${ }^{18}$. Our technique of reconstruction is similar to Bosworth technique with little modification by spreading the tip of the harvested flap in fanned out manner over bridging tissue which helps in better integration of graft and making surface smooth. We trimmed excess tissue from the flap to avoid volume effect and over stuffing which can lead to skin closure tightening and further skin necrosis. We didn't use any other augmentation like flexor hallucis longus, peroneus, plantaris tendon as our harvested graft after reconstruction provided good strength conserving foot and ankle tendon motor function.

Our mean AOFAS score was 95.2, at par with the literature and with F.Khiami et al in particular ${ }^{19}$ which improved significantly from mean 65.6. In our series Mean time to surgery was 5.16 months (range 1.5-12) and with average rupture gap of $5.33 \mathrm{~cm}$. As these factors increase the risk of postoperative complications, our study results were comparable with other studies due to simplicity in technique, less complexity and managing larger gaps in even longer neglected cases without harvesting and augmenting with other tendons.

\section{Conclusion}

Achilles tendon is one of the most common ruptured tendons and can be debilitating if left untreated. Management of neglected ruptures is difficult with multiple treatment options depending on the rupture gap and state of the remaining tissue. Reconstructing with turning down the harvested gastrosoleus flap can bridge the ruptured gap of varying size, restore length, sparing the foot $\&$ ankle muscles with reasonable good outcome.

\section{Acknowledgment}

We would like to thank Dr Srikanta Kanungo for statistical analysing the results of this study.

Sources of support: self, no grant

\section{References}

1. Habusta, S. (1995). Bilateral simultaneous rupture of the Achilles tendon. A rare traumatic injury. Clin Orthop Relat Res, 320, pp. 231-234

2. Arner O, Lindholm A, Orell SR. Histologic changes in subcutaneous rupture of the Achilles tendon; a study of 74 cases. Acta Chir Scand 1959;116:48490

3. Edna TH. Non-operative treatment of Achilles tendon ruptures. Acta Orthop Scand 1980;51:991-3

4. Inglis AE, Sculco TP. Surgical repair of ruptures of the tendo Achillis. Clin Orthop 1981;156:160-9

5. Mao H, Shi Z, Xu D, Liu Z. Neglected Achilles Tendon Rupture Treated with Flexor Hallucis Longus transfer with two turndown gastrocnemius fascia flap and reinforced with plantaris tendon; Acta Orthop Belg. 2015 Sep;81(3):553-60.

6. Maffulli, N. (1996). Clinical tests in sports medicine: more on Achilles tendon. $\mathrm{Br} \mathrm{J}$ Sports Med, 30, pp. 250

7. Arner, O. \& Lindholm, A. (1959). Subcutaneous rupture of the Achilles tendon; a study of 92 cases. Acta Chir Scand, 116, supp 239, pp. 1-51.

8. Barnes, M. \& Hardy, A. (1986). Delayed reconstruction of the calcaneal tendon. $\mathrm{J}$ Bone Joint Surg Br, 68, 1, pp. 121-124.

9. Pradeep jain, Parthapratim Dutta, Prabal Goswami, Amol M Patel, Shammi Purwar, Vaibhav Jain; Management of Neglected Achilles Tendon Division: Assessment of Two Novel and Innovative Techniques; Advances in Orthopedic Surgery Volume 2014, Article ID 729397, 6 pages. 
10. Wegrzyn J, Luciani JF, Philippot R, BrunetGuedj E, Moyen B, Besse JL. Chronic Achilles tendon rupture reconstruction using a modified flexor hallucis longus transfer [published online ahead of print August 21, 2009]. Int Orthop. 2010; 34(8):1187-1192

11. H.B. Kitaoka, I.J. Alexander, R.S. Adelaar, J.A. Nunley, M.S. Myerson, M. Sanders Clinical rating systems for the ankle-hindfoot, midfoot, hallux, and lesser toes Foot Ankle Int, 15 (1994), pp. 349353

12. G. M. M. J. Kerkhoffs, P. A. A. Struijs, E. L. F. B. Raaymakers, and R. K. Marti, "Functional treatment after surgical repair of acute Achilles tendon rupture: wrap vs walking cast," Archives ofOrthopaedicandTraumaSurgery, vol.122, no.2,pp.102-105, 2002.

13. Kannus P, Jozsa L. Histopathological changes preceding spontaneous rupture of a tendon, J Bone Joint Surg Am 1991;73:1507-25.

14. Takao M, Ochi M, Naito K, Uchio Y, Matsusaki M, Oae K. Repair of neglected Achilles tendon rupture using gastrocnemius fascial flaps [published online ahead of print October 25, 2002]. Arch Orthop Trauma Surg. 2003; 123(9):471-474.

15. Wegrzyn J, Luciani JF, Philippot R, BrunetGuedj E, Moyen B, Besse JL. Chronic Achilles tendon rupture reconstruction using a modified flexor hallucis longus transfer [published online ahead of print August 21, 2009]. Int Orthop. 2010; 34(8):1187-1192

16. E. Abraham and A. M. Pankovich, "Neglected rupture of the Achilles tendon: treatment by V-Y tendinous flap," Journal of Boneand Joint SurgeryA, vol.57, no.2,pp.253-255,1975.
17. Lindholm, "A new method of operation in subcutaneous rupture of the Achilles tendon," Acta Chirurgica Scandinavica, vol.117,pp.261-270,1959.

18. D. M. Bosworth, "Repair of defects in the tendoachilles," The Journalo f Bone\& Joint Surgery, vol.38,pp.111-114,1956.

19. F Khiami, M Di Schino, E Sariali, D Cao, E Rolland, Y Catonné, "Treatment of chronic Achilles tendon rupture by shortening suture and free sural triceps aponeurosis graft", Orthopaedics \& Traumatology, Surgery \& Research: OTSR 2013, 99 (5): 585-91 